\title{
Surface Performance and Optimization of Nickel Titanium Alloy Electropolishing Parameters
}

\author{
Yongqi Wang, Xiuting Wei*, Zhiyong Li, Xuemin Jing, Zhikang Gong, Chuan Liu \\ Shandong University of Technology, School of Mechanical Engineering, 266 xincun west road, \\ 255049, Zibo, China \\ *E-mail: wxt@sdut.edu.cn
}

doi: $10.20964 / 2021.07 .23$

Received: 1 March 2021 / Accepted: 23 April 2021 / Published: 31 May 2021

\begin{abstract}
Nickel titanium alloys are widely used in different fields, such as biomedicine, machinery and electronics, and aerospace, because of their shape memory effect, superelasticity, and corrosion resistance. Surface treatment on nickel titanium alloy is necessary to reduce metal ion released in human tissues and prevent human poisoning and organ failure. This paper proposes an electropolishing method for optimizing the surface quality of nickel titanium alloy pipes. A hybrid electropolishing solution suitable for nickel titanium alloy pipes was determined through experiments. The four factors affecting the electropolishing process were analyzed and the best polishing parameters were obtained through orthogonal experiment and single factor experiment. Quantitative statistics revealed that the material removal of the electropolishing method is controllable. Finally, a nickel titanium alloy pipe with low surface roughness $(40.7 \mathrm{~nm})$ and good surface morphology was obtained.
\end{abstract}

Keywords: Electropolishing; Nickel titanium alloy pipe; Surface properties; Ra; Material removal

\section{FULL TEXT}

(C) 2021 The Authors. Published by ESG (www.electrochemsci.org). This article is an open access article distributed under the terms and conditions of the Creative Commons Attribution license (http://creativecommons.org/licenses/by/4.0/). 